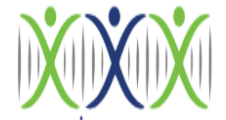

iRASD
Pakistan Journal of Humanities and Social Sciences

Volume 9, Number 3, 2021, Pages 265-272

Journal Homepage:

https://journals.internationalrasd.org/index.php/pjhss
PAKISTAN JOURNAL OF

HUMANITIES AND SOCIAL

SCIENCES (PJHSS)

\title{
An Analysis of the Circumstances of Tolerance Status among University Students
}

\author{
Fahad Maqbool ${ }^{1}$, Shehzad Ahmed ${ }^{2}$, Khadija Akram ${ }^{3}$ \\ ${ }^{1}$ Ph.D. Scholar Government College University Faisalabad, Pakistan. \\ ${ }^{2}$ Assistant Professor, Faculty of Education, University of Okara, Pakistan. Email: dr.shehzad@uo.edu.pk \\ ${ }^{3}$ Lecturer in Applied Linguistics Kinnaird College for Women Lahore, Pakistan. Email: khadija.akram@kinnaird.edu.pk
}

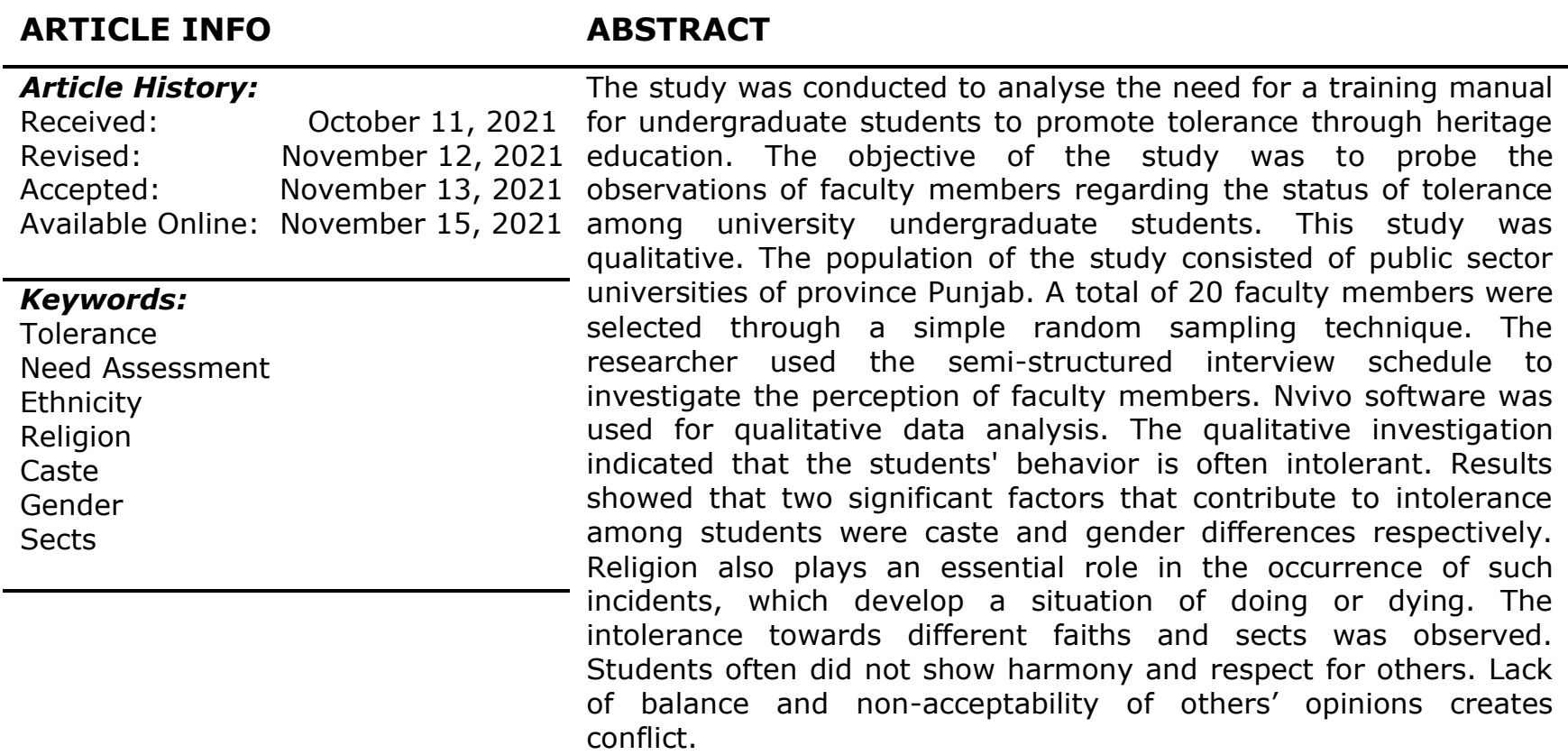

(c) 2021 The Authors, Published by iRASD. This is an Open Access Article under the Creative Common Attribution Non-Commercial 4.0 Corresponding Author's Email: dr.shehzad@uo.edu.pk

\section{Introduction}

Tolerance is the societal traditional word applied to those who may believe, behave or act in ways of which one may not approve. It is a process that leads the acceptance respect and even a judgment in different ways of life. Tolerance is a principal of judgment which reflects propositional reasoning that is logical and verifiable which leads people to understand how their actions can affect the lives of others (Colesante \& Biggs, 1999).

The human rights observance for tolerance does not mean to bear the societal discrimination or to weaken the one's belief. Tolerance means everyone is entitled to rights without discrimination and everyone has freedom to have their own belief and also accepts that others have their own belief. It means to acknowledge the fact that human beings are logically varied in their looks, situation, language, actions and ideals and have the right to live as they live. Enforcing one's views on other, does not mean tolerance (Peterson, 2003). Tolerance is a unique way of thinking and acting. Distinguishes human power with wisdom and to act bravely is called tolerance. Social tolerance is a process that emphasizes respect for others while living in one society. And recognizes the differences between them Social tolerance requires that people in society live with each other without fear (Chadha \& Schatz, 2004). Social resilience is a fundamental perspective for promising majority rules systems and can be utilized as a key thought in mounting cultural arrangements (Chadha \& Schatz, 2004). Social resilience alludes to a person's availability to relate with somebody on assorted levels: from just living in the comparable neighborhood, to living next passage, to turning out to be close connects with that individual (Schnittker, 2004). 
In Pakistan latest and serious issue was the religious differences. Christians, Atheists, Ahmadi Muslims and Hindus were commonly ignored. Due to different religious faiths they were commonly reputes for loans, jobs, housing and other basic facilities. Minority worship places like Ahmadi worship places, Christian church and sect base mosques were commonly attacked (Simşek \& Elitok Kesici, 2012). Commonly two words used for the personality that are character and individuality. Individuality represents the characteristics or distinctive personality and Character of an individual is the abilities that distinguish him/her from others in phase of religion, tolerant or intolerant (Sinclair et al., 2001).

Williams (1998) recommended that commonly tolerance based on moral values i.e. respect for elders and it mostly important on social practice. The researcher was against the political practice of tolerance, as he suggests that moral toleration may not be able to fulfill the demands of liberal philosophers. The practice of tolerance cannot only continuous by untainted norms hidden values of independence mixed by capitals. Williams's resists that the nonviolent social cooperation and coexistence assured by liberal civilizations may be able to be achieved virtue of tolerance as respect for elders while we should work for adopting tolerant behavior for others.

Society needed a pathway that must be widely acceptable and motivate for tolerance. Hirschman discovers the history of the idea that person's self-interest can respond their violent and hateful desires. The negative desires as yearning the power and splendor, dangerous for human beings. It also defined as social disorder if we leave unchecked violent passions and negative desires. While individual's hobbies, interests and their social activities should be observed as peaceful, innocent and harmless. This type of soothing environment can create a better foreign trade between different communities (Hirschman et al., 2013). Dees (1999) applied the Hirschman ideas in the literature of religious tolerance. Dees described that the level of concern in economic status can motivate tolerance. Capitalism helps the persons of various religious groups to interact with ignores religion completely. He concluded that if people send more time to enhance their economic interest they should pay less interest on religious variances.

Tolerance is an integral part of a peaceful society. The people who are living in multicultural societies with several religious practices there have to show respect towards each other. Although, Pakistan is a country where the majority of the population is Muslim but still minorities like Christian, Sikh, and Hindus cannot be ignored. They all are sharing the same educational institutions like elementary, secondary and higher education institutions as well as other local and national services. In the last few decades, cases of intolerance are observed in Pakistan among different religions but interestingly, within religious differences are also experienced. Keeping in view the importance and need of tolerance in the existence of peace and harmony in society, the study was conducted under the title of "Analyze the circumstances of tolerance status among university students". The core objective of the study was to investigate the perceptions of faculty members regarding status of tolerance among university students

\section{Research Design}

The qualitative research design was followed to conduct this study. The researcher used different data analysis techniques. The researcher investigated the perceptions of faculty members regarding the status of tolerance among university students. With the help of an interview schedule, interviews were conducted with faculty members for the sake of qualitative data collection.

\subsection{Participation}

Higher education commission has reported that 6115 full time faculty members were working in general universities of province Punjab (Higher Education Commission, 2019). Four universities were selected through simple random sampling technique. Interviews were taken from the four public sector universities in province Punjab; including Government College University Faisalabad, University of Okara, Okara, Quaid-i-Azam University, Islamabad and Bahudin Zikria University, Multan. Further, faculties of social sciences of the mentioned universities were selected purposively. Five faculty members from each university were 
interviewed. In total, 15 male and 5 female full time faculty members aged between 30 to 55 years were interviewed. They belonged to different qualification groups including Doctorate and Post Doctorate. The faculty members were chosen on their willing to participate in data collection activity. The interviewer approached them through reference and few of them participated voluntarily after understanding the importance of the research. The researcher and interviewer did not know any of them before.

Table 3: Distribution of Faculty Members from different Universities

\begin{tabular}{ll}
\hline Name & Number of Faculty member \\
\hline Government College University Faisalabad, Faisalabad & 5 \\
University of Okara, Okara & 5 \\
Quaid-i-Azam University, Islamabad & 5 \\
Buhadin Zikria University, Multan & 5 \\
Total & 20 \\
\hline
\end{tabular}

The above-mentioned figure shows the distribution of faculty members from four selected universities. 5 faculty members were interviewed from Government College University Faisalabad. Whereas, the same number of faculty members (5) were interviewed from the other three institutions as well.

\section{$2.2 \quad$ Procedure}

A semi-structured interview schedule was developed with the help of a review of literature, concerned supervisor and field experts. These interviews were conducted in a silent and peaceful environment to increase the quality of data. Most of the faculty members were available in their office cabins and tried their best to minimize any kind of distortion and disturbance during the interview. The average duration for interviews remained between 25 minutes to 40 minutes. The basic theme of the interview was to investigate the status of students towards tolerance. It included circumstances, incidents and factors of intolerance that contribute to the intolerant reaction. The university environment about tolerance, the role of curriculum towards tolerance, need of training manual regarding tolerance, the role of heritage education in tolerance development and also suggestions about the training manual topics were also part of the interview. The face to face interview was conducted by the researcher. The hard copy of the interview questions was provided to them before starting interviews. The questions were developed in the English language while the Urdu translation was also available on the given copy. When the interviewers faced any confusion or misunderstanding regarding interview questions or terminology than the researcher elaborate it in detail to help them to resolve their confusion and misunderstandings. The interviews were recorded in electronic storage devices through mobile phone recorder with interviewers' prior permission. The researcher ensured the interviewers that the data will be only used for research purpose and their identity will not be disclosed without their permission. The recorded interviews were transcript in English in a hard form. Few interviews were recorded in the Urdu language. The researcher transcribes that into the Urdu language and then translated into the English language.

\subsection{Analytical Approach}

NVivo 11 was used as facilitator in qualitative data analysis. The interviews were transcribed in MS Word files. NVivo text analysis function helped researcher in extraction of themes that are related to basic idea of the project. Initially we developed word tag cloud (Figure 1) to reveal the roots of different themes in different sizes that show the most expressive words used by the faculty member about the status of tolerance among students according to frequency of their occurrence and repetition.

Among also area argument relations attentions attitude background bad Bloch battle beat intolerance behavior beliefs belongs blasphemy Bradari bravery brothers canteens Caste changes cheap christens Choudary system clashes classrooms Co-Education Co-Existence communications communities comparisons conflicts conversations cultures depends discriminations domestics education environment adventurers family federations females fights financial friendships Gender genetics geographic girls Government grouping habits sects illiteracy incidents injustice jokes linguistics Religions nonverbally peoples problems province religious rights society students system thinking university 


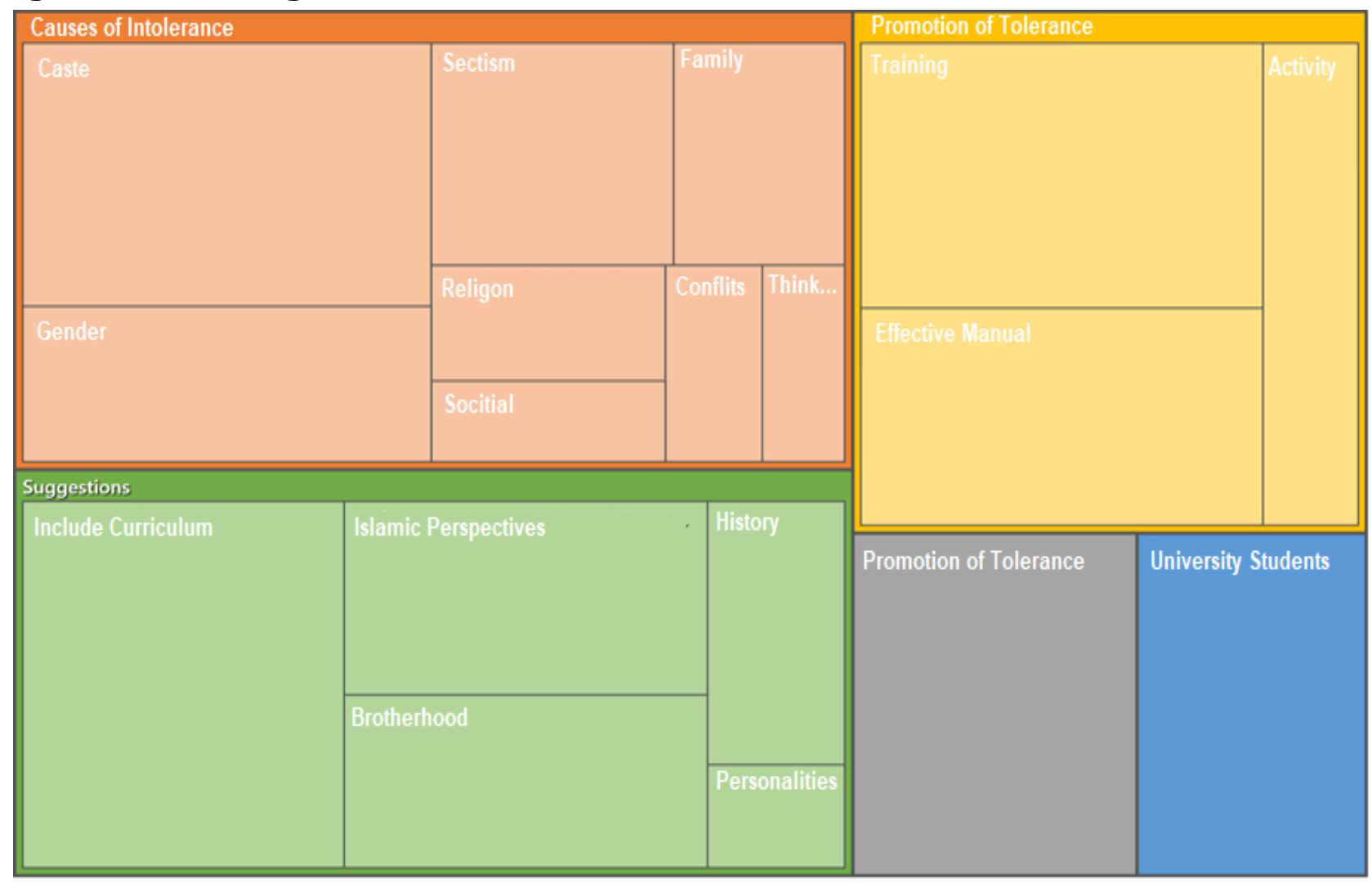

The word tag cloud shows the use of frequently used words regarding the status of tolerance with a different theme. It exhibits the word intolerance, students, university, caste, sect, gender, and religions are the most repeated words used by the interviewees. These words showed that mainly the interviewees focus on these words to present the concept of our research. The other frequently used words were change, comparison, conflict, females, financial, geographic, society, thinking, and backgrounds, etc. These highlighted words have shown a significant relationship with the concept of tolerance. Although the uses of few main themes regarding the logic of intolerance are caste, gender, sects, religions, society, backgrounds, thinking, family, environment, geography, comparisons, conflicts, education, relations, females, education, christens, changes, financial, grouping, co-education, and aggression, etc.

Further, in data analysis, we created word tree maps to illustrate various patterns of respondents' reflections and locations of key frequent words in these patterns. The tree maps show the causes of intolerance that include the concept of caste, as a major noted factor. Students have no patience due to their class distribution in society. Few castes are considering themselves as superior while their attitude reflects that they consider others inferior. The students who belong to upper castes are creating a strange discriminated environment in institutions. They often engaged in fighting and tragedies because of their ego issues. Another important factor that is found in the tree map is gender. Students did not tolerate the insult that is done by the opposite gender. They became more intolerant towards the opposite gender. Religious factors are also important as results showed that students have zero or minimum tolerance towards other religions. However, sect beliefs are highly reported during the interview sessions. Family, conflicts, and thinking are the other major causes of intolerance. The results for the interview question regarding the promotion of tolerance were asked and the answer showed that there is a need for an effective training manual. An effective training manual is highly recommended in the current scenario but it should be activity-based. It is suggested that the curriculum should include the topics of Islamic perspectives, the passion of brotherhood, historical stories regarding tolerance and especially discuss those personalities that serve human beings. 


\section{Finding of the Study}

The findings of qualitative data analysis on the perception of the teachers towards the status of tolerance among university students are presented below. The purpose of the research is to explore the prevailing situation of intolerance, causes of intolerance and preventive measures that can use to control the situation. The results for the above-mentioned questions are discussed below:

\subsection{Circumstances about the status of tolerance}

The faculty members of different universities elaborated on the different views about the circumstances regarding the status of tolerance among students. A male Assistant professor of education viewed the status of tolerance, "It is witnessed that in the university, sometimes students have shown tolerance while sometimes they didn't. Students come from different regions and this creates cultural diversity. They show their own culture. After establishing networks in university, they form their unions and create disputes. So, it is not tolerance". The faculty member further elaborated that if the students' background is related to the immoral and negative norms and values, this must urge them to create the incidents of intolerance through unions. A female Professor of sociology of Public Sector University expressed her views regarding the status of tolerance. She said that "If you ask for my opinion then I would say that nowadays the level of tolerance and leniency among students has decreased considerably. They indulged in fights at small and irrelevant things. They have been quite protective of their own rights, but being this hot-headed is also quite harmful to them. If they rashly react to small matters in a negative manner then that is quite harmful to them as well. So I would say that the current generation university students have a weak tolerance level". She also elaborated that students filled their minds with their misunderstanding for a long time and after that their reaction becomes intolerant. Another Assistant Professor of Education told that tolerance is the core element for teachers, students as well as our educational administrators. The score of tolerance must be observed in our daily professional life. In my university, if I calculate randomly than around 80 percent of students are showing intolerance frequently while 20 percent have a different attitude. Most of the time, these 20 percent are humble and tolerant. They have extra leadership qualities." Tolerance is the core element for all human beings but unfortunately, we can't show this in many situations.

\subsection{Incidents of intolerance}

The research findings show that the ratio of the reported incidents of intolerance is very huge. A male Associate Professor of Sociology says that "Unionism in university creates intolerance among students. The students who join unions, they show less tendency to tolerance. I observed an incident in my Public Sector University, students were involved in a minor dispute and this became their ego issue. They often discriminate themselves as they are Sindhis and they are Blochis, they are Punjabi and they are Pashtun. On this issue, they started fighting and called the police. Few of them were injured and in this result, the university got closed. So, such kind of intolerant incidents are examples that need to be minimized". The faculty member expressed that unions are making students intolerant in universities. A male Assistant Professor of Islamic Studies demonstrated their "Yeah, it happens sometimes student's react oddly; they even never behave properly with their teachers too. Student's grouping is the main reason behind it. Religion, politics and uneven status rise to conflict among students. Especially, debates on political affairs arise conflict among them and it ends on strikes. This especially happens in government universities".

A Female Assistant Professor showed her views in these words; "Not only students but also teachers showed intolerant behavior towards the students". The interaction between colleagues is prejudiced and sometimes abusive too. They discussed their issues with students and involved them too that make students aggressive and disappointed as well". Female Assistant Professor from the Political Science department argued that intolerance is geographic as students came from different regions, follow different cultures and believers of different sects. On these bases, sometimes these incidents happened to whom we can be termed as intolerance" Another male Assistant Professor from the Education department depicts his thoughts like; "difference in point of view creates clashes. The students who support their ethnic, sect, and religion often want to win conversational conflicts. In case of failure in the discussion, they behave unethically. They become violent verbally as well as physically than can harm both parties". 
There are many factors found in the analysis that are highly responsive to makes students intolerant. A male Assistant Professor from a Public Sector University expressed that "the caste system plays a significant role. The caste system is the root cause of intolerance and discrimination in Pakistan. This makes people proud and arrogant and they show intolerance and aggression towards other castes like if I'm "Awan" I would obviously be brave; but they might be showing bravery in the wicked way" A male Associate Professor of Sociology argue "Geographical differences are the foremost reason of intolerance as people coming from other regions and they form their lobbies and pressure groups. If a single person is facing the issue then they will work as a pressure group and support their region. This often happens in canteens and playgrounds of the Universities. In our cultural festivals, these types of fights took place specifically on the name of the region, and generally on the name of caste, creed, and sect. There is recognition like Bloch students, Pashtuns, etc. They are often recognizing each other with their castes like "kharal bradari", "Jutt bradari".

The second major reason for discrimination after the region is the caste system". Many faculty members expressed that the caste is the main issue about the incidents of intolerance. A female Assistant Professor Sociology says "There are many factors affecting tolerance. In my point of view, two factors are directly involved in this matter one is caste and second is gender-differences. Male students did not give space to female students. Finally, female students start fighting for their equal rights and this situation creates intolerance in classes as well. An Associate Professor of Education expressed that "Difference among their faiths, lack of acceptability about the other beliefs and sects are the main reasons for intolerance. As all Muslims are following different Imams. The people who follow Imam Abu Hanifa called Hanfi, so there are other Imams as well and people follow them. People often did not show tolerance to other followers. That's why the incidents of intolerance also exist within religion".

The above-discussed factors are the influential factors that are frequently observed in the discussion of experts. These investigations help to fulfill the objectives of the study. These determinants are responsible for creating intolerance in the universities specifically and in society generally.

\section{Discussion}

Tolerance is one of those qualities that substantial to a society nationally and internationally. The world becomes smaller today as a result of globalization. More people from different nations, cultures, religions, and lifestyles are working together and living in the same neighborhoods than ever before. As a result of this, a single incident of intolerance can damage the image of society as a country cannot hide their situation.

The current practice of intolerance reported in Pakistani Public Sector University. A student of Abdul Wali Khan University (AWKU) Mardan, department of Mass Communication Mashal Khan, had been beaten and murdered by an annoyed crowd on April 13, 2017 (Dawn, 2018). The incident of Asiya Maloma has happened when she was feeling thirsty and reach into the water tub for drinking water. But the very bad incident happened when Muslims did not permit her because she was Christian. Asiya Maloma described this incident with very strong words about blasphemy. Asiya Maloma's words make a very poor impression of Pakistani society in terms of tolerance. So, it is a very critical condition of religious extremism in the country (BBC News, 2019).

Gender discrimination has a large influence on education as well as the economic development of a country. In developing countries, especially with the Muslim majority, the rank of women education is low as compare to others. The male population often did not show tolerance for women's development (Yumusak, Bilen, \& Ates, 2013).

Similarly, Pakistani society is also not very friendly and supportive of women's development. Religion, region, caste; and gender are the foremost determinants of intolerance in our study. The faculty members of different universities elaborated on different views about the circumstances of tolerance. The faculty member stated that if the student's background has an influential effect on their behavior. Their different norms and ethics played a vital role 
in the occurrence of such kind of incidents. Students did not forget their revenge and reacted intolerantly even after passing time. Tolerance is the core element for all human being but unfortunately, we can't show tolerance in most of the situations. The ratio of the incidents of intolerance is very hugely reported during research.

The interviewers expressed about the unions in universities that enhance intolerance among students. The student-teacher relationship did not report frequently. often, students reacted to their personal and egoistic issues. The geographical differences are also important as in Pakistan, the culture varies according to geographical boundaries. Students from different regions react differently to different problems. On this basis, sometimes unpleasant circumstances are created to whom we coined a term called intolerance. Domestic problems help them to react violently. They often behave rudely in their homes and as a result of that, they failed to distinguish between their personal and professional affairs and reactions. The caste system is the root cause of discrimination. People developed their lobbies and pressure groups that support them in such kind of activities. In cultural festivals of universities, fights based on gender, caste and region happened usually. Religion, gender, region, sect, and caste remain the significant determinants of intolerance in our study. The difference in cultural norms and values is also considerably effecting the incidence of intolerant. These intolerant incidents often changed in long term revenge and fights. The difference among their faiths, their lack of acceptability about other religious beliefs and sects are the reasons for intolerance. All Muslims follow the different Imams and they often did not accept and tolerate the teachings and beliefs of other groups. The discussed factor elaborates on the major factors that are frequently used during the investigation of the objectives of the study and these factors are indirectly played a vital role to create intolerance in the university sector.

\section{Conclusion and Recommendations}

The study was conducted to analyze the circumstance of students regarding the tolerance in their behavior and social life. A qualitative research design was followed to conduct this study. 20 faculty members from four different public universities were interviewed with the help of a semi-structured interview schedule. Their responses were analyzed with the help of Nvivo software. All the interviewers were holding PhD degrees. 15 of them were male and 5 were female faculty members. The faculty members of selected universities responded that students often showed intolerant behavior. Religion, gender, region, sect, and caste remained the significant determinants of intolerance in our study. The difference in cultural norms and values is also considerably affecting the ratio of intolerant incidences. These intolerant incidents often changed in long term revenge and fights. The difference among their faiths, their lack of acceptability about other religious beliefs and sects are the reasons for intolerance. All Muslims follow the different Imams and they often did not accept and tolerate the teachings and beliefs of other groups. The discussed factor elaborates on the major factors that are frequently used during the investigation of the objectives of the study and these factors are indirectly played a vital role to create intolerance in the university sector. The faculty member stated that if the student's background has an influential effect on their behavior. Their different norms and ethics played a vital role in the occurrence of such kind of incidents. Students did not forget their revenge and reacted intolerantly even after passing time.

Tolerance is the core element for all human being but unfortunately, we can't show tolerance in most of the situations. The ratio of the incidents of intolerance is very hugely reported during research. Students unions in universities support intolerance among students. The student-teacher relationship did not report frequently. Often, students reacted to their personal and egoistic issues. The geographical differences are also important as in Pakistan; the culture varies according to geographical boundaries. Students from different regions react differently to different problems. Domestic problems help them to react violently. They often behave rudely in their homes and as a result of that, they failed to distinguish between their personal and professional affairs and reactions. In cultural festivals of universities, fights based on gender, caste and region happened usually. Religion, gender, region, sect, and caste remain the significant determinants of intolerance in our study. The difference in cultural norms and values is also considerably affecting the incidence of intolerant. These intolerant incidents often changed in long term revenge and fights. The difference among their faiths, their lack of acceptability about other religious beliefs and sects are the reasons for intolerance. All Muslims follow the different Imams and they often did not accept and tolerate 
the teachings and beliefs of other groups. The discussed factor elaborates on the major factors that are frequently used during the investigation of the objectives of the study and these factors are indirectly played a vital role to create intolerance in the university sector

\section{References}

Chadha, E., \& Schatz, L. (2004). Human dignity and economic integrity for persons with disabilities: a commentary on the Supreme Court's decisions in Granovsky and Martin. Journal of Law and Social Policy. 19, 94-122. https://researchdirect.westernsydney.edu.au/islandora/object/uws\%3A12646/

Colesante, R. J., \& Biggs, D. A. (1999). Teaching about Tolerance with Stories and Arguments. Journal of Moral Education, 28(2), 185-199. https://doi.org/10.1080/030572499103205

Bhatti, A. M., Abbas, F., \& Rana, A. M. K. (2020). An Empirical study of learning styles used by undergraduate English learners in public sector colleges in Pakistan. Elementary Education Online, 19(3), 1864-1875.

Nazir, S., Abbas, F., \& Naz, F. (2020). Historical development of orthography in English and impact of computer-mediated communication (CMC) on the emerging orthographic patterns in English. PalArch's Journal of Archaeology of Egypt/Egyptology, 17(11), 162-175.

Abbas, F., Aslam, S., \& Khan, R. A. M. (2011). Code-mixing as a communicative strategy among the university level students in Pakistan. Language in India, 11 (1), 95-108.

Chohan, M. N., Abbas, F., \& Saleem, M. (2018). CALL as a tool in teaching EFL in Pakistani religious institutes (Madaris): A survey of issues and challenges. Al Qalam, 23(1), 355-368.

Abbas, F., Rana, A. M. K., Bashir, I., \& Bhatti, A. M. (2021). The English language proficiency as a global employment skill: the viewpoint of Pakistani academia. Humanities and Social Sciences Review. 9 (3), 1071-1077.

Dees, R. H. R. (1999). Establishing Toleration. Political Theory, 27(5), 667-693. https://doi.org/10.1177/0090591799027005004

Higher Education Commission. (2019). Universities Statistics. https://www.hec.gov.pk/english/universities/Pages/AJK/UniversitiesStatistics.aspx

Hirschman, A. O., Adelman, J., \& Sen, A. (2013). The Passions and the Interests: Political Arguments for Capitalism before Its Triumph (Revised ed. edition). Princeton University Press.

Peterson, S. (2003). Tolerance. Beyond Intractability. https://www.beyondintractability.org/essay/tolerance

Schnittker, J. (2004). Social Distance in the Clinical Encounter: Interactional and Sociodemographic Foundations for Mistrust in Physicians. Social Psychology Quarterly, 67(3), 217-235. https://doi.org/10.1177/019027250406700301

Simşek, G., \& Elitok Kesici, A. (2012). Heritage Education for Primary School Children Through Drama: The Case of Aydın, Turkey. Procedia - Social and Behavioral Sciences, 46, 3817-3824. https://doi.org/10.1016/j.sbspro.2012.06.153

Sinclair, J. M., Wilkes, G. A., \& Krebs, W. A. (2001). Collins concise dictionary. HarperCollins.

Williams, B. (1998). Toleration: An Elusive Virtue. Princeton University Press. https://www.degruyter.com/view/books/9781400822010/9781400822010.18/97814 00822010.18.xml 